\title{
Effects of 3-month Mediterranean-type diet on postprandial TAG and apolipoprotein B48 in the Medi-RIVAGE cohort
}

\author{
Catherine Defoort, Stéphanie Vincent-Baudry and Denis Lairon* \\ INRA, UMR 1260 and INSERM ERL1025 "Nutriments Lipidiques et Prévention des Maladies Métaboliques", \\ Faculté de Médecine, IPHM-IFR 125, 27 Boulevard Jean Moulin, Marseille, 13385 Cedex 05, France
}

Submitted 13 May 2011: Accepted 12 August 2011

\begin{abstract}
Objective: To determine the postprandial lipaemia response before and after intervention with healthy diets in the Medi-RIVAGE cohort of subjects with moderate risk factors of CVD.

Design: One hundred and thirty-five adults (fifty-two men and eighty-three women) followed either a Mediterranean-type (MED) diet or a low-fat American Heart Association-type diet in a parallel design for 3 months. At entry and after 3 months, lipids, glucose and insulin were measured in the fasting samples; TAG and apolipoprotein B48 (ApoB48; a marker of intestinally derived chylomicrons) levels were measured in the fasting and postprandial samples after a standard test meal. Results: The MED diet only lowered $(P<0 \cdot 028)$ fasting TAG and both diets reduced TAG and ApoB48 levels $5 \mathrm{~h}$ after the test meal. The overall $5 \mathrm{~h}$ postprandial ApoB48 response (area under curve (AUC)/incremental AUC) was lowered after both diets but this effect was more marked after the MED-diet intervention. Whatever the TAG level at entry, normo- and hyper TAG subjects showed a reduction in the postprandial ApoB48 levels after 3-month diets. BMI at entry did not impact the effect of diets given subjects with $\mathrm{BMI}<$ or $>25 \mathrm{~kg} / \mathrm{m}^{2}$ showed reduced postprandial ApoB48. Men and women displayed comparable postprandial changes after dietary challenges.

Conclusions: A MED diet appears efficient to improve postprandial lipaemia, a recently acknowledged CVD risk, in men and women at moderate cardiovascular risk.
\end{abstract}

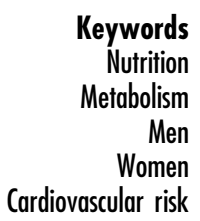

Postprandial lipaemia has received increasing attention during the past two decades ${ }^{(1,2)}$. Indeed, following a typical fat-containing meal (30-60 g fat), circulating TAG shows a marked elevation within $1-2 \mathrm{~h}$ and can remain elevated for $5-8 \mathrm{~h}$ in healthy subjects and longer in dyslipidaemic patients ${ }^{(3,4)}$. On the basis of dietary habits, it is clear that the dominant state of TAG metabolism for most humans is postprandial ${ }^{(1,5-7)}$.

The specificity of the postprandial period is a physiological transient accumulation of TAG-rich lipoprotein (TRL) particles in the circulation as provided by both the liver (very LDL) and the small intestine (chylomicrons secreted after lipid digestion and absorption $)^{(1,8)}$. The capacity of individuals to regulate circulating TAG levels, that is, to secrete and clear TRL postprandially, is obviously an important reflection of their metabolic homeostasis as challenged by dietary intakes ${ }^{(9)}$.

It is now well recognised that elevated postprandial lipaemia and TRL is a characteristic metabolic abnormality of a number of lifestyle-related diseases and conditions that are associated with increased cardiovascular morbidity and mortality ${ }^{(10-12)}$. Exacerbated postprandial lipaemia has been repeatedly associated with cardiovascular risk during clinical studies ${ }^{(13)}$. Moreover, recent and large epidemiological surveys have clearly evidenced the strong association between the extent of non-fasting TAG and the relative risk for cardiovascular events in men and women ${ }^{(14,15)}$.

Thus, the habitual high-saturated fat, high-carbohydrate/ sugar diets (and sedentary lifestyles) that typify the present time in industrialised countries are prone to cause exacerbated postprandial lipaemia ${ }^{(1,5-7)}$, even in healthy subjects. Only a limited number of clinical studies have addressed the effect of chronic dietary regimen on the extent of postprandial lipaemia. While most of them have tested the effects of changes in single nutrients or fibres as reviewed $^{(16)}$, very few have investigated the effects of global dietary challenges on postprandial lipid metabolism ${ }^{(17)}$. Hence, during the 3-month Medi-RIVAGE intervention study ${ }^{(18)}$, we aimed to investigate the influence of dietary changes on postprandial lipid metabolism in subjects at moderate cardiovascular risk. We hypothesised that substituting a Western-type diet for either a Mediterranean (MED) diet or a low-fat diet alters the postprandial levels of circulating TAG or apolipoprotein B48 (ApoB48), a specific marker of intestinally derived TRL particles ${ }^{(19)}$. 


\section{Subjects and methods}

\section{Subjects and study design}

The design and methods of the Medi-RIVAGE intervention study have been reported previously in detail ${ }^{(17)}$. Briefly, volunteers were men and women aged 22-70 years who met at least one of the following eligibility criteria: fasting plasma cholesterol concentration of $6.5-7.7 \mathrm{mmol} / \mathrm{l}$; TAG concentration of $2 \cdot 1-4.6 \mathrm{mmol} / \mathrm{l}$; glucose concentration of $6 \cdot 1-6 \cdot 9 \mathrm{mmol} / 1$; blood pressure between 140-180 and 90-105 mmHg; BMI $>27 \mathrm{~kg} / \mathrm{m}^{2}$ or family history of CVD. Subjects treated with hypolipaemic or hypoglycaemic drugs were excluded.

At entry, eligible volunteers relied on a Western-type diet as reported previously in detail ${ }^{(17)}$. They were provided with nutritional recommendations and follow-up by dietitians. The subjects were randomly assigned to consume one of the two slightly restricted and reducedfat diets for 3 months, that is, either an MED diet adapted from the traditional model ${ }^{(20)}$ or an adaptation of the commonly prescribed low-fat American Heart Association-type diet (LFAT). To summarise the published detailed changes in nutrient intakes after 3 months in 169 subjects $^{(18)}$, the two intervention diets had comparable reduced total fat ( $\sim 34 \%$ energy), saturated fat ( $\sim 10 \%$ energy) and cholesterol ( $\sim 190 \mathrm{mg} / \mathrm{d})$, and comparable increased PUFA ( $\sim 6 \%$ energy) and increased MUFA in the MED group (up to $15 \cdot 6 \%$ energy). Fruit, vegetable and fish intakes increased in both diet groups, whereas nut and fibre intakes increased in the MED group only. In fact, the nutrient and fibre intakes did not markedly differ between the two diet groups as reported elsewhere ${ }^{(18)}$.

One hundred and thirty-five volunteers (fifty-two men and eighty-three women) enrolled in the postprandial study provided a full data set including postprandial tests after 3-month dietary intervention. At entry and after 3-month intervention diets, fasting blood samples were taken after overnight fast and before the morning standard test meal, which consisted of rusks (six servings), sunflower margarine (40 g), sugar (10 g), ham (30 g) and tea or coffee ad libitum in line with previous studies as reviewed $^{(21)}$. The test meal contained $2792 \mathrm{~kJ}$ ( $\left.667 \mathrm{kcal}\right)$ including 53\% energy as fat, $40 \%$ as carbohydrates and $7 \%$ as protein and was eaten in $20 \mathrm{~min}$. After ingestion of this light test meal, subsequent blood samples were drawn after $2 \cdot 5$ and $5 \mathrm{~h}$ as used previously ${ }^{(22)}$.

Informed consent was obtained from each subject and the study was approved by the institution's ethics committee (ethics committee no. 98/25).

\section{Analytical methods}

At entry and after 3 months, biochemical analyses were performed as described previously ${ }^{(18)}$. Briefly, plasma and serum samples were immediately separated from whole blood by centrifugation. Glucose, insulin and TAG were determined using routine laboratory techniques in fasting and postprandial plasma samples from all subjects and ApoB48 quantification was performed using a competitive ELISA ${ }^{(23)}$.

\section{Statistical analyses}

Statistical analyses were performed using the Statistical Package for Social Sciences statistical software version 17·0 (SPSS Inc., Chicago, IL, USA).

Absolute postprandial changes are given as concentration values. The data for postprandial parameters response following the test meal were expressed as area under the curve (AUC; 0-5 h) and were calculated by the trapezoidal method. Incremental AUC (IAUC) was calculated by subtracting the fasting concentration value.

Identified covariables such as sex, BMI, variation in body weight, alcohol consumption, smoking status (smoker/ former smoker/never smoker) and menopausal status in women (yes/no or treated) were entered into the models.

Time effect within diet group was calculated using paired $t$ test. Group effect at entry was assessed by univariate ANOVA. General linear models (GLM) were used to compare the postprandial response profiles between the different groups (diet groups, the low- and high-BMI groups, the low- and high-TAG groups). Two-tailed values of $P<0.05$ were considered significant.

\section{Results}

The characteristics of the 135 volunteers at entry are shown in Table 1 . We did not observe significant differences between the two diet groups for the markers of fasting lipaemia (TAG and ApoB48) and postprandial lipaemia (AUC/IAUC for TAG and ApoB48) and for most lipid parameters. The HOMA score (Homeostasis Model Assessment of Insulin Resistance) reflecting the insulinoresistance status was not different in the two groups. HDL and LDL cholesterol levels were slightly different between the two diet groups.

\section{Influence of 3-month intervention diets on fasting and postprandial parameters}

In the present study, after 3-month consumption of the intervention MED or LFAT diets, the MED group only elicited a small but significant decrease in fasting TAG levels $(\Delta \mathrm{TAG}=-0 \cdot 15(\mathrm{SD} \quad 0 \cdot 07) \mathrm{mmol} / \mathrm{l} \quad v \cdot-0 \cdot 13 \quad(\mathrm{SD}$ $0 \cdot 09) \mathrm{mmol} / \mathrm{l}$ for MED and LFAT groups, respectively; Table 2). The changes observed in postprandial TAG and ApoB48 levels after the test meal are shown in Fig. 1. After 3-month intervention, TAG levels significantly decreased $5 \mathrm{~h}$ after the test meal in both intervention groups $(\Delta \mathrm{TAG}=-0.33(\mathrm{sD} 0 \cdot 09) \mathrm{mmol} / \mathrm{l} v .-0 \cdot 27(\mathrm{sD} 0 \cdot 10) \mathrm{mmol} / \mathrm{l}$ for MED and LFAT groups, respectively). Nevertheless, the changes in TAG AUC or TAG IAUC after 3 months were not significantly different from those at entry, whatever the group. 
After 3-month consumption of the MED or LFAT diets, no significant change in fasting ApoB48 levels was observed (Fig. 1, Table 2). After 3-month intervention, subjects in the MED group had a significantly reduced ApoB48 level $(\Delta$ ApoB $48=-0 \cdot 013$ (SD $0 \cdot 09) \mathrm{mg} / \mathrm{l} v$. -0.010 (sD $0 \cdot 09) \mathrm{mg} / \mathrm{l}$ for MED and LFAT groups, respectively) for $2.5 \mathrm{~h}$ after the test meal. Five hours after the test meal, ApoB48 levels markedly and significantly decreased in both diet groups $(\Delta \mathrm{ApoB} 48=-0 \cdot 30$ (SD $0 \cdot 05) \mathrm{mg} / \mathrm{l} v \cdot-0 \cdot 19(\mathrm{sD} 0.05) \mathrm{mg} / \mathrm{l}$ for MED and LFAT groups, respectively). After 3-month intervention, the ApoB48 AUC and IAUC showed a marked and significant decrease in both groups ( $\triangle$ ApoB48 AUC: $-1 \cdot 00$ (SD $0 \cdot 22) \mathrm{mg} / 1 v \cdot-0 \cdot 45(\mathrm{SD} 0 \cdot 16) \mathrm{mg} / \mathrm{l}$ for MED and LFAT diets,

Table 1 Characteristics of subjects in MED and LFAT intervention groups at entry

\begin{tabular}{|c|c|c|c|c|c|}
\hline & Diet & $n$ & Mean & SD & $P$ \\
\hline \multirow[t]{2}{*}{ Age (years) } & MED & 72 & $51 \cdot 50$ & $10 \cdot 50$ & NS \\
\hline & LFAT & 63 & $52 \cdot 80$ & $9 \cdot 20$ & \\
\hline \multirow[t]{2}{*}{ BMI $\left(\mathrm{kg} / \mathrm{m}^{2}\right)$} & MED & 72 & $28 \cdot 43$ & $4 \cdot 27$ & NS \\
\hline & LFAT & 63 & $28 \cdot 18$ & $4 \cdot 70$ & \\
\hline \multirow[t]{2}{*}{ Waist-to-hip ratio } & MED & 69 & 0.88 & 0.14 & NS \\
\hline & LFAT & 59 & 0.89 & $0 \cdot 13$ & \\
\hline \multirow[t]{2}{*}{ АроB48 } & MED & 72 & 0.22 & 0.17 & NS \\
\hline & LFAT & 60 & 0.25 & $0 \cdot 18$ & \\
\hline \multirow[t]{2}{*}{ ApoB48 IAUC } & MED & 72 & 0.37 & 0.38 & NS \\
\hline & LFAT & 60 & 0.28 & 0.25 & \\
\hline \multirow[t]{2}{*}{ TAG } & MED & 72 & $1 \cdot 57$ & 0.97 & NS \\
\hline & LFAT & 59 & 1.44 & 0.77 & \\
\hline \multirow[t]{2}{*}{ TAG IAUC } & MED & 69 & 0.58 & $0 \cdot 76$ & NS \\
\hline & LFAT & 58 & 0.53 & 0.67 & \\
\hline \multirow[t]{2}{*}{ Cholesterol } & MED & 72 & $6 \cdot 61$ & 1.01 & NS \\
\hline & LFAT & 63 & $6 \cdot 45$ & 0.95 & \\
\hline \multirow[t]{2}{*}{ HDL cholesterol } & MED & 72 & 1.45 & 0.38 & 0.023 \\
\hline & LFAT & 63 & 1.63 & 0.50 & \\
\hline \multirow[t]{2}{*}{ LDL cholesterol } & MED & 71 & $4 \cdot 46$ & 0.93 & 0.022 \\
\hline & LFAT & 62 & 4.09 & 0.91 & \\
\hline \multirow[t]{2}{*}{ Glucose } & MED & 72 & $5 \cdot 20$ & 0.60 & NS \\
\hline & LFAT & 63 & $5 \cdot 22$ & 0.60 & \\
\hline \multirow[t]{2}{*}{ Insulin } & MED & 72 & $10 \cdot 18$ & $5 \cdot 84$ & NS \\
\hline & LFAT & 63 & $10 \cdot 54$ & $7 \cdot 34$ & \\
\hline \multirow[t]{2}{*}{ HOMA score } & MED & 72 & $2 \cdot 37$ & $1 \cdot 50$ & NS \\
\hline & LFAT & 63 & $2 \cdot 48$ & $1 \cdot 85$ & \\
\hline
\end{tabular}

MED, Mediterranean diet; LFAT, low-fat American Heart Association-type diet; ApoB48, apolipoprotein B48; IAUC, incremental area under curve. Subjects in MED diet ( $n 72)$ and LFAT diet ( $n 63)$ groups at entry with thirty men and forty-two women, respectively, in MED group and twenty-two men and forty-one women in LFAT group. $P$ values give significance between the two diet groups using ANOVA model. respectively, and $\Delta$ ApoB48 IAUC : $-0 \cdot 27(\mathrm{sD} 0 \cdot 06) \mathrm{mg} / \mathrm{l} v$. $-0 \cdot 11(\mathrm{SD} 0 \cdot 05) \mathrm{mg} / \mathrm{l}$ for MED and LFAT groups, respectively; Table 2).

Repeated measures (0 and 3 months) GLM indicated that the type of diet modulated the reduction in ApoB 48 IAUC and AUC (time and diet, $P=0.045$ and 0.046 , respectively) but not for TAG variables. Thus, the two diet groups have been merged for further analysis on postprandial parameters, with diet used as a covariable.

\section{Effects offasting TAG, BMI, waist-to-bip ratio and} gender at entry on the postprandial parameters

As shown in Fig. 2a (left panel), after stratifying the cohort ( $n$ 135) according to the fasting TAG level at entry, subjects with a higher fasting TAG level $(>1.7 \mathrm{mmol} / \mathrm{l} ; n$ 34) also had higher TAG levels $2 \cdot 5$ and $5 \mathrm{~h}$ after the test meal at entry $(P<0 \cdot 001$ for each time point). This was also observed after 3-month dietary intervention $(P<0 \cdot 001$ for each time point). Nevertheless, the level of fasting TAG at entry did not alter the TAG IAUC or AUC after 3-month dietary intervention.

At entry, subjects with a higher fasting TAG level also presented a higher fasting ApoB48 level $(P=0.009)$ as shown in Fig. 2a (right panel). ApoB48 levels 2.5 and $5 \mathrm{~h}$ after the test meal did not differ between the low- and highTAG groups. After 3-month dietary intervention, both groups showed a significant and comparable decrease in ApoB48 IAUC $(P=0 \cdot 001)$ and fasting ApoB48 levels were no longer different between the low- and high-TAG groups.

There were no significant differences between the two TAG subgroups for other fasting lipid parameters, age or BMI.

As shown in Fig. 2b (left panel), when stratifying the cohort according to subjects' BMI at entry, after 3-month dietary intervention overweight/obese subjects (with BMI $>25 \mathrm{~kg} / \mathrm{m}^{2}$ ) presented higher fasting TAG and higher postprandial TAG at the $2.5 \mathrm{~h}$ time point $(P=0.003$ and $0 \cdot 012$, respectively). After dietary intervention, the reductions in TAG IAUC were not significant whatever the BMI group. As shown in Fig. 2b (right panel), subjects with low and high BMI had comparable ApoB48 levels at fasting and postprandially. After 3-month dietary intervention, the two BMI groups showed a significant and comparable decrease in ApoB48 IAUC $(P=0 \cdot 001)$.

Table 2 Effect of MED $(n 72)$ and LFAT $(n$ 63) diets on fasting and postprandial ApoB48 and TAG

\begin{tabular}{|c|c|c|c|c|c|c|c|c|c|c|c|}
\hline & \multicolumn{2}{|c|}{ MED (month 0) } & \multicolumn{2}{|c|}{ MED (month 3) } & \multirow[b]{2}{*}{ Time effect } & \multicolumn{2}{|c|}{ LFAT (month 0) } & \multicolumn{2}{|c|}{ LFAT (month 3) } & \multirow[b]{2}{*}{ Time effect } & \multirow[b]{2}{*}{ Time $\times$ diet } \\
\hline & Mean & $\mathrm{SD}$ & Mean & $\mathrm{SD}$ & & Mean & SD & Mean & SD & & \\
\hline Fasting B48 & 0.22 & $0 \cdot 17$ & 0.26 & $0 \cdot 23$ & NS & $0 \cdot 25$ & $0 \cdot 18$ & 0.26 & $0 \cdot 21$ & NS & NS \\
\hline IAUC B48 & 0.39 & 0.39 & $0 \cdot 10$ & 0.32 & $<0.001$ & 0.27 & $0 \cdot 25$ & $0 \cdot 16$ & $0 \cdot 22$ & 0.021 & 0.045 \\
\hline Fasting TAG & $1 \cdot 58$ & 0.97 & $1 \cdot 43$ & 0.99 & 0.028 & $1 \cdot 44$ & $0 \cdot 77$ & $1 \cdot 31$ & 0.63 & NS & NS \\
\hline IAUC TAG & 0.58 & $0 \cdot 76$ & 0.56 & $0 \cdot 61$ & NS & 0.52 & 0.67 & 0.53 & $0 \cdot 47$ & NS & NS \\
\hline
\end{tabular}

MED, Mediterranean diet; LFAT, low-fat American Heart Association-type diet; ApoB48, apolipoprotein B48; IAUC, incremental area under curve.

Fasting and postprandial ApoB48 (mg/l) and TAG (mmol/l).

Time effect was calculated using paired $t$ test; time $\times$ diet significance was calculated using general linear models. 


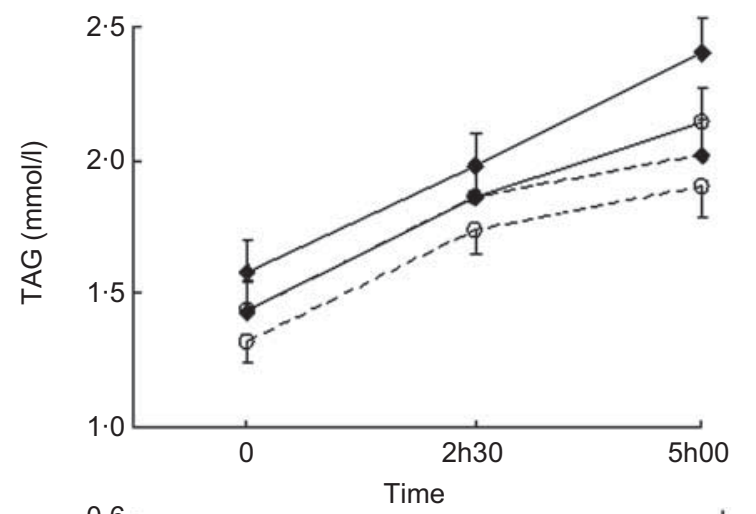

\begin{tabular}{|c|c|c|}
\hline Time & MED diet & LFAT diet \\
\hline Oh & 0.028 & NS \\
\hline $2 \mathrm{~h} 30$ & NS & NS \\
\hline 5 h00 & 0.001 & 0.012 \\
\hline IAUC & NS & NS \\
\hline AUC & NS & NS \\
\hline
\end{tabular}

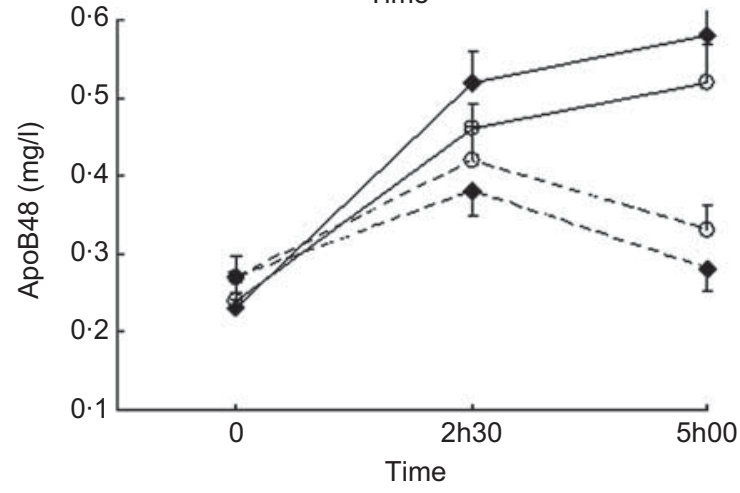

\begin{tabular}{|c|c|c|}
\hline Time & MED diet & LFAT diet \\
\hline Oh & NS & NS \\
\hline $2 \mathrm{~h} 30$ & 0.002 & NS \\
\hline $5 \mathrm{~h} 00$ & $<0.001$ & 0.001 \\
\hline IAUC & $<0.001$ & 0.021 \\
\hline AUC & $<0.001$ & 0.007 \\
\hline
\end{tabular}

Fig. 1 Variation of postprandial TAG (upper panel) and postprandial apolipoprotein B48 (apoB48; lower panel) after a test meal in the Mediterranean-type diet (MED; $\diamond$ ) and low-fat American Heart Association-type diet (LFAT; $\bigcirc)$ groups at entry (-) and after 3-month diet (---). The table inserts give the significance level of the change after 3-month diet intervention for each time point (fasting, $2.5 \mathrm{~h}$ or $5 \mathrm{~h}$ postprandialy) and for the overall $5 \mathrm{~h}$ postprandial period (area under curve (AUC) and incremental AUC (IAUC). Values are expressed as mean and SEM

The waist-to-hip ratio (WHR) reflects abdominal obesity. After stratification of the cohort according to the presence or absence of this risk factor (WHR $>1 \cdot 0$ in men and $>0.8$ in women), only women without this risk factor showed a significant lower fasting TAG at entry $(0.99$ (SD 0.097) v. $1.57(\mathrm{SD} 0.11) \mathrm{mmol} / \mathrm{l}$ for WHR $<0.8$ and $>0.8$ respectively, $P<0.001)$ and a significant variation after the dietary intervention regarding the TAG IAUC $(-0.04(\mathrm{sD} 0.08) v .0 .30(\mathrm{sD} 0.09) \mathrm{mmol} / 1$ for WHR $<0.8$ and $>0 \cdot 8$ respectively, $P=0 \cdot 016)$ after adjustment for age and menopausal status. No statistical difference was observed for ApoB48 parameters.

Regarding gender, we observed that fasting TAG at entry was significantly higher in men compared with women (1.83 (SD 0.15) v. 1.31 (SD 0.08) mmol/l, $P=0 \cdot 001$ ), but no other difference was observed between genders regarding TAG AUC/IAUC and ApoB48 parameters at entry and after the dietary intervention.

\section{Discussion}

We have previously reported the lowering effects of the 3-month dietary interventions on fasting total and LDL cholesterol, TAG, glucose and insulin levels in the
Medi-RIVAGE cohort $^{(18)}$. In the present paper, we aimed to determine the effect of two global diets on postprandial parameters in 135 volunteers. We clearly show herein the favourable effects of the MED diet, and to a lesser extent of the LFAT diet, on relevant postprandial parameters such as TAG and ApoB48.

We observed that the MED diet, and to a lesser extent the low-fat diet, markedly blunted the response to the test meal by significantly reducing the TAG and ApoB48 levels after $5 \mathrm{~h}$ (Fig. 1). This time point is of clear importance because it reflects the second part of the postprandial event, that is, the clearance phase of TRL particles. It has been repeatedly shown that an exaggerated delayed postprandial TAG and TRL excursion is associated with an increased CVD risk ${ }^{(1,13-15,24)}$. This was the case at entry when the subjects involved exhibited a noticeable clearance defect with elevated $5 \mathrm{~h}$ TAG levels. In a recent meta-analysis of about hundred trials, it was indeed found that the $4 \mathrm{~h}$ time point is the best suited to detect abnormal postprandial lipaemia ${ }^{(25)}$. We observed that the TAG level $5 \mathrm{~h}$ postprandially was reduced by $13.7 \%$ after the MED diet and $12 \cdot 5 \%$ after the LFAT diet. Considering the available evidence associating elevated/delayed postprandial or non-fasting TAG and the risk for CHD in both men and women, the present data support the new idea 
(a) With stratification on fasting TAG at entry
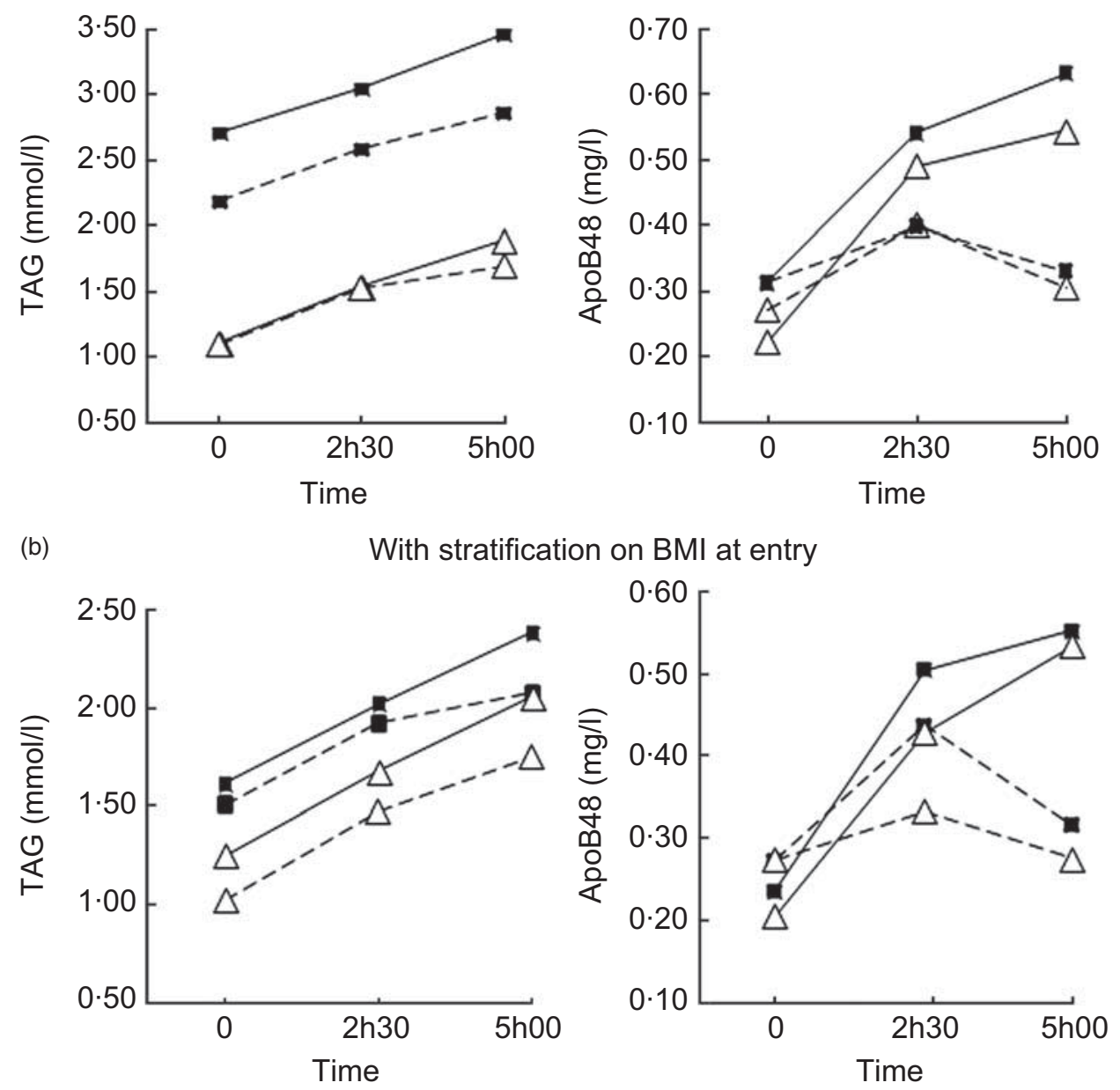

Fig. 2 Impact of fasting TAG ( $\boldsymbol{\square}, \mathrm{TAG}>1.7 \mathrm{mmol} / \mathrm{l} ; \Delta$, TAG $<1.7 \mathrm{mmol} / \mathrm{l} ;$ a) or BMI $\left(\boldsymbol{\square}, \mathrm{BMI}>25 \mathrm{~kg} / \mathrm{m}^{2} ; \Delta, \mathrm{BMl}<25 \mathrm{~kg} / \mathrm{m}^{2} ; \mathrm{b}\right)$ at entry on postprandial TAG (left) and postprandial apolipoprotein B48 (ApoB48; right) responses to a 3-month Mediterranean-type diet ( $\_$, at entry; -.--, after 3 months). Values are expressed as mean and SEM

that an MED diet markedly reduces the postprandial lipaemia risk factor and, thus, can be protective against CVD. A previous study comparing European with northern or southern dietary patterns reported a difference in postprandial TAG kinetics in the two groups ${ }^{(26)}$. This is in line with numerous other studies reporting a reduced cardiovascular mortality and events in subjects relying on a traditional MED diet ${ }^{(27,28)}$.

It was also very interesting to observe that at the same time (i.e. $5 \mathrm{~h}$ postprandially), the ApoB48 level was markedly reduced after the MED diet and to a lesser extent the LFAT diet. Therefore, the blunting of the ApoB48 level after $2.5 \mathrm{~h}$ as well as the overall $5 \mathrm{~h}$ postprandial ApoB 48 accumulation under the MED diet $(-74 \cdot 4 \%)$ is a remarkable observation. The LFAT diet only reduced ApoB 48 AUC by $41.7 \%$. Because ApoB48 is a specific marker of instestinally derived chylomicrons in humans, this indicates that an MED diet markedly limits the number of chylomicron particles in the circulation postprandially. This could account for native chylomicrons as secreted by the small intestine after meal fat digestion and/or clearance of chylomicrons remnants that are quickly generated upon endovascular lipolysis of native chylomicrons. Although no clear explanations are available regarding chylomicron remnant clearance, the reduction of insulinaemia and HOMA score reported in the subjects on the MED diet ${ }^{(18)}$ can be associated with a decrease in chylomicron ApoB48 synthesis, as demonstrated by others ${ }^{(29)}$.

Taken together, the markedly reduced late accumulation of both TAG and ApoB48 levels elicited by the MED diet supports its beneficial effect on lipid metabolism. It could also play a role in explaining the observed inverse relationship between obesity, especially central obesity, and adherence to a traditional MED diet as repeatedly reported $^{(30,31)}$. Indeed, filling adipocytes with TAG is a postprandial phenomenon wherein TRL TAG are released 
from TRL and taken up by adipocytes while hyperinsulinaemia block the intracellular TAG hydrolysis. In fact, there are number of foods and nutrients (fatty acids, carbohydrate, fibres) that could play a role in the global beneficial effect of the MED diet as observed on postprandial lipaemia ${ }^{(1,5-7)}$. This remains to be further documented.

Obesity is known to promote exaggerated postprandial lipaemia ${ }^{(22,32-34)}$ and a positive relationship between BMI and plasma TAG levels has been observed. Most subjects included in the Medi-RIVAGE cohort were overweight $(70 \%)$ and lost weight (mean $=-3.4 \mathrm{~kg}$ ) after the 3-month diet. We found (Fig. 2) that whatever the subject's BMI at entry $\left(<\right.$ or $>25 \mathrm{~kg} / \mathrm{m}^{2}$ ), the 3 -month regimen promoted a higher clearance of ApoB48-containing particles based on the reduced ApoB48 IAUC or AUC. Thus, the overweight/ obese as well as the lean subjects benefited from the dietary change accompanied by a small weight loss.

Regarding the impact of fasting TAG on the subsequent postprandial response (Fig. 2), we observed that those subjects with abnormally high fasting TAG have an exaggerated postprandial TAG response in agreement with the literature ${ }^{(1,35)}$. It is noteworthy that the lowering effect of the 3-month diet was comparable in subjects with normal or elevated TAG.

In conclusion, we report herein for the first time the efficiency of an MED in improving postprandial lipaemia, a recently acknowledged CVD risk, in men and women at moderate cardiovascular risk.

\section{Acknowledgements}

The authors declare that they have no conflict of interest. All authors conceived and designed the study. C.D. and D.L. analysed, interpreted the data and wrote the paper. The authors thank Claudine Antona for her technical help.

\section{References}

1. Lopez-Miranda J, Williams C \& Lairon D (2007) Dietary, physiological, genetic and pathological influences on postprandial lipid metabolism. Br J Nutr 98, 458-473.

2. Zilversmit DB (1979) Atherogenesis: a postprandial phenomenon. Circulation 60, 473-485.

3. Groot PH, van Stiphout WA, Krauss XH et al. (1991) Postprandial lipoprotein metabolism in normolipidemic men with and without coronary artery disease. Arterioscler Thromb Vasc Biol 11, 653-662.

4. Karpe F, Steiner G, Uffelman K et al. (1994) Postprandial lipoproteins and progression of coronary atherosclerosis. Atherosclerosis 106, 83-97.

5. Lairon D, Play B \& Jourdheuil-Rahmani D (2007) Digestible and indigestible carbohydrates: interactions with postprandial lipid metabolism. J Nutr Biochem 18, 217-227.

6. Williams CM (1997) Postprandial lipid metabolism: effects of dietary fatty acids. Proc Nutr Soc 56, 679-692.

7. Roche HM, Zampelas A, Knapper JM et al. (1998) Effect of long-term olive oil dietary intervention on postprandial triacylglycerol and factor VII metabolism. Am J Clin Nutr 68, 552-560.
8. Lairon D (2008) Macronutrient intake and modulation on chylomicron production and clearance. Atheroscler Suppl 9, 45-48.

9. Silva KD, Wright JW, Williams CM et al. (2005) Meal ingestion provokes entry of lipoproteins containing fat from the previous meal: possible metabolic implications. Eur J Nutr 44, 377-383.

10. O'Keefe JH, Gheewala NM \& O'Keefe JO (2008) Dietary strategies for improving post-prandial glucose, lipids, inflammation, and cardiovascular health. J Am Coll Cardiol 51, 249-255.

11. Tiret L, Gerdes C, Murphy MJ et al. (2000) Postprandial response to a fat tolerance test in young adults with a paternal history of premature coronary heart disease - the EARS II study (European Atherosclerosis Research Study). Eur J Clin Invest 30, 578-585.

12. Alipour A, Elte JW, van Zaanen HC et al. (2008) Novel aspects of postprandial lipemia in relation to atherosclerosis. Atheroscler Suppl 9, 39-44.

13. Patsch JR, Miesenbock G, Hopferwieser T et al. (1992) Relation of triglyceride metabolism and coronary artery disease. Studies in the postprandial state. Arterioscler Thromb Vasc Biol 12, 1336-1345.

14. Bansal S, Buring JE, Rifai N et al. (2007) Fasting compared with nonfasting triglycerides and risk of cardiovascular events in women. JAMA 298, 309-316.

15. Nordestgaard BG, Benn M, Schnohr P et al. (2007) Nonfasting triglycerides and risk of myocardial infarction, ischemic heart disease, and death in men and women. JAMA 298, 299-308.

16. Mekki N, Dubois C, Charbonnier M et al. (1997) Effects of lowering fat and increasing dietary fiber on fasting and postprandial plasma lipids in hypercholesterolemic subjects consuming a mixed Mediterranean-Western diet. Am J Clin Nutr 66, 1443-1451.

17. Vincent S, Gerber M, Bernard MC et al. (2004) The Medi-RIVAGE study (Mediterranean Diet, Cardiovascular Risks and Gene Polymorphisms): rationale, recruitment, design, dietary intervention and baseline characteristics of participants. Public Health Nutr 7, 531-542.

18. Vincent-Baudry S, Defoort C, Gerber M et al. (2005) The Medi-RIVAGE study: reduction of cardiovascular disease risk factors after a 3-mo intervention with a Mediterranean-type diet or a low-fat diet. Am J Clin Nutr 82, 964-971.

19. Redgrave TG (2004) Chylomicron metabolism. Biochem Soc Trans 32, 79-82.

20. Willett WC, Sacks F, Trichopoulou A et al. (1995) Mediterranean diet pyramid: a cultural model for healthy eating. Am J Clin Nutr 61, Suppl. 6, 1402S-1406S.

21. Lairon D, Lopez-Miranda J \& Williams C (2007) Methodology for studying postprandial lipid metabolism. Eur J Clin Nutr 61, 1145-1161.

22. Guerci B, Paul JL, Hadjadj S et al. (2001) Analysis of the postprandial lipid metabolism: use of a 3-point test. Diabetes and Metab 27, 449-457.

23. Lorec AM, Juhel C, Pafumi Y et al. (2000) Determination of apolipoprotein B-48 in plasma by a competitive ELISA. Clin Chem 46, 1638-1642.

24. Weintraub MS, Grosskopf I, Rassin T et al. (1996) Clearance of chylomicron remnants in normolipidaemic patients with coronary artery disease: case control study over three years. BMJ 312, 935-939.

25. Mihas C, Kolovou GD, Mikhailidis DP et al. (2011) Diagnostic value of postprandial triglyceride testing in healthy subjects: a meta-analysis. Curr Vasc Pharmacol 9 , 271-280.

26. Zampelas A, Roche H, Knapper JM et al. (1998) Differences in postprandial lipaemic response between Northern and Southern Europeans. Atherosclerosis 139, 83-93. 
27. Keys A, Menotti A, Karvonen MJ et al. (1986) The diet and 15-year death rate in the seven countries study. Am J Epidemiol 124, 903-915.

28. Sofi F, Cesari F, Abbate R et al. (2008) Adherence to Mediterranean diet and health status: meta-analysis. BMJ 337, a1344.

29. Duez H, Pavlic M \& Lewis GF (2008) Mechanism of intestinal lipoprotein overproduction in insulin resistant humans. Atherosclerosis Suppl 9, 33-38.

30. Buckland G, Bach A \& Serra-Majem L (2008) Obesity and the Mediterranean diet: a systematic review of observational and intervention studies. Obes Rev 9, 82-93.

31. Romaguera D, Norat T, Mouw T et al. (2009) Adherence to the Mediterranean diet is associated with lower abdominal adiposity in European men and women. J Nutr 139, $1728-1737$.
32. Mekki N, Christofilis MA, Charbonnier M et al. (1999) Influence of obesity and body fat distribution on postprandial lipemia and triglyceride-rich lipoproteins in adult women. J Clin Endocrinol Metab 84, 184-191.

33. Raben A, Andersen HB, Christensen NJ et al. (1994) Evidence for an abnormal postprandial response to a high-fat meal in women predisposed to obesity. Am J Physiol 267, E549-E559.

34. Potts JL, Coppack SW, Fisher RM et al. (1995) Impaired postprandial clearance of triacylglycerol-rich lipoproteins in adipose tissue in obese subjects. Am J Physiol 268, E588-E594.

35. Sato I, Ishikawa Y, Ishimoto A et al. (2009) Significance of measuring serum concentrations of remnant lipoproteins and apolipoprotein B-48 in fasting period. $J$ Atheroscler Thromb 16, 12-20. 